\title{
The Khuff Multi-dimensional: Results From Outcrop Analogue Studies in Oman
}

Michael Pöppelreiter (Shell, <m.poppelreiter@shell.com>) on behalf of the Shell-University of Tübingen Khuff team

The Permian-Triassic Khuff platform is a classical epeiric sequence with limited seismicscale reservoir geometries. It is referred to by some as the thickest "pile of grainstones on earth" and shows significant variations in productivity. To better understand these, grainstone dimensions and distributions were investigated in outcrops to:

- Establish a regional tie point for the Khuff stratigraphic framework.

- Describe grainstone architecture on different scales.

- Correlate reservoir bodies on sub-seismic scale (architecture of epeiric deposits).

The study area is the Al Jabal al-Akhdar in the Sultanate of Oman. Six outcrop sections of Lower to Upper Khuff time-equivalent strata (each about 1,000 m thick) were investigated. The study was designed:

- Multi-scale: from near-well bore to regional scale ('Russian-doll' approach).

- Multi-disciplinary: sedimentology-bio-chemo-sequence stratigraphy-petrophysics.

- Multi-dimensional: from 1-D sections to 3-D digital models.

\section{Results:}

- Khuff analogues in the Oman Mountains constitute the seaward margin of the Permian-Triassic platform.

- Study established the first complete Permian-Triassic outcrop section in the Middle East (biostratigraphy, chemostratigraphy and sequence stratigraphy).

- Two second-order supersequences were interpreted in the Khuff equivalent strata with maximum flooding in the KS6 and KS2 sequences.

- Interpreted time-lines allowed a regional correlation of six Khuff sequences.

- The presence of several important regional biostratigraphic markers (benthic foraminifera) has been reported for the first time in the Al Jabal al-Akhdar region.

- Nested 3-D models ('Russian-doll' approach) were created and predictive rules and trends established that describe grainstone architecture and geometries from 10s to $>$ 10,000 s meters.

- Geological concepts suggest potential for stratigraphic traps in the KS6 and KS5 sequences: (onlap and bypass channels) and potential source rock intervals around the KS6 to KS2 mfs.

- Grainstone attributes (e.g. aspect ratio, grain types, texture) are controlled by stratigraphic and paleotectonic position. 